\title{
PENGUJIAN USER EXPERIENCE PADA APLIKASI SMART HOME MENGGUNAKAN USE QUESTIONNAIRE
}

\author{
${ }^{1)}$ Muhammad Bambang Firdaus, ${ }^{2)}$ Irfan Putra Pratama, ${ }^{3)}$ Andi Tejawati, \\ 4) M Khairul Anam, ${ }^{5)}$ Fadli Suandi \\ ${ }^{1,2,3)}$ Informatika, Fakultas Teknik, Universitas Mulawarman \\ 4) Teknologi Informasi, Stmik Amik Riau \\ 5) Teknik Multimedia dan Jaringan, Politeknik Negeri Batam \\ ${ }^{1,2,3)}$ Kampus Gn. Kelua Jl. Kuaro - Kalimantan Timur - Indonesia \\ 4) Jl. Purwodadi Indah - Riau - Indonesia \\ ${ }^{5}$ Batam Centre, Jl.Ahmad Yani - Kepulauan Riau - Indonesia \\ E-mail : ${ }^{1)}$ bambangf@fkti.unmul.ac.id, ${ }^{2)} f f a n p r a t a m a @ g m a i l . c o m,{ }^{3)}$ tejawatiandi@gmail.com \\ ${ }^{4)}$ khairulanam@sar.ac.id, ${ }^{5)}$ fadli.suandi@polibatam.ac.id
}

\begin{abstract}
ABSTRAK
Smart Home merupakan teknologi terintegrasi dengan layanan jaringan rumah, termasuk dengan jaringan pada aplikasi smartphone. Penelitian ini dilakukan untuk membuat desain user interface Aplikasi Smart Home berbasis android yang mudah dipahami oleh pengguna untuk mengontrol sistem dan menguji User Experience terhadap desain aplikasi smart home. Metode dalam mengumpulkan data yang digunakan ialah studi pustaka, angket, dan pengamatan (observasi). Dalam metode pengembangan sistem menggunakan Linear Sequential Model. Aplikasi yang digunakan dalam pembuatan desain dan aplikasi smart home antara lain Android Studio, Sublime, Xampp, Adobe Xd, dan Adobe Illustrator. Metode pengujian yang di gunakan antara lain Usability testing dan Pengukuran Usability menggunakan USE Questionnaire. Dalam penelitian ini menghasilkan sebuah desain Aplikasi Smart Home yang dapat digunakan pengguna dengan mudah dalam mengontrol sistem.
\end{abstract}

Kata Kunci: User Interface, User Experience, Smart Home, USE Questionnaire

\begin{abstract}
Smart Home is an integrated technology with home network services, including the network on smartphone applications. This research was conducted to design an Android-based Smart Home application user interface that is easily understood by users to control the system and test the User Experience on the smart home application design. The data collection methods used were questionnaires, observations, and literature studies. For the system development method using the Linear Sequential Model / Waterfall Model method. Applications used in making designs and smart home applications include Android Studio, Sublime, Xampp, Adobe Xd, and Adobe Illustrator. The testing methods used include Usability testing and Usability Measurement using the USE Quistionnaire. This research produces a Smart Home application design that can be used by users to easily control the system.
\end{abstract}

Keyword: User Interface, User Experience, Smart Home, USE Questionnaire

\section{PENDAHULUAN}

Sejak tahun 1960-an, teknologi Smart Home telah hadir dan berkembang. Tetapi sumber daya diperlukan untuk membangun rumah cerdas pada waktu itu dengan biaya yang tidak murah. Smart Home ialah teknologi yang memiliki integrasi dengan layanan jaringan rumah, yang bisa meningkatkan kualitas hidup. Rumah Pintar adalah suatu bentuk peralatan listrik rumah tangga, sistem penerangan atau kontrol sistem keamanan rumah tangga dan pemantauan otomatis yang dapat dikelola dan dipantau langsung sesuai keinginan pemiliknya [1]. Saat ini ada sistem rumah pintar yang menggunakan kabel dan nirkabel. Meminimalkan penggunaan listrik dalam penggunaan dan pelaksanaan ruangan. Smart home adalah rumah yang saling terhubung (eHome) dengan lingkungan yang digerakkan oleh sistem [2]. Rumah cerdas disebut cerdas karena semua aktivitas di 
komputer dapat dipantau [3]. Rumah cerdas ini terdiri dari sejumlah perangkat terhubung yang dirancang untuk meningkatkan kualitas hidup pemilik rumah [4]. Sistem ini dapat dikontrol secara otomatis oleh rumah tangga cerdas mulai dari kontrol lampu, suhu ruangan, multimedia dan perangkat keselamatan [5].

Semakin beragamnya aplikasi mobile menjadi salah satu penyebab meningkatnya pengguna smartphone di dunia [6]. Dalam aplikasi yang berbeda, pengembang aplikasi seluler semakin bersaing untuk mendapatkan aplikasi yang menarik, yang satu dalam penampilan. Antarmuka pengguna adalah bagian penting dari sebuah sistem atau aplikasi. UI merupakan bagian dari sistem yang digunakan untuk berinteraksi langsung dengan pengguna. Oleh karena itu, desain $U I$ merupakan salah satu daya tarik utama untuk aplikasi seluler pada khususnya [7].

Warna merupakan fitur desain yang sangat penting karena digunakan untuk menciptakan kesan di benak audiens pada elemen desain. Perasaan bahwa warna memberi otak manusia reaksi khusus [8]. Warna adalah karakteristik yang sangat tajam yang mempengaruhi kepekaan penglihatan dan karena itu meningkatkan kesan atau perasaan[9]. Fungsi warna sebagai identitas atau pembeda, pemberian informasi atau rangsangan emosional bertanggung jawab atas reaksi atau rangsangan tersebut, sehingga memudahkan khalayak untuk mengenali objek [10].

Salah satu hal terpenting adalah usability ketika membangun sistem yang baik. Pengalaman pengguna menunjukkan bahwa pengalaman pengguna dalam pengoperasian sistem membuat sistem mudah digunakan dan efisien, pengalaman pengguna berperan dalam pengembangan sistem [11]. Dikatakan mudah menggunakan suatu aplikasi atau sistem apabila Fitur dan menu dalam aplikasi atau sistem terlihat bagus dan menarik [12].

Dalam bentuk feedback dari aplikasi, pengguna akan memberikan feedback positif yang dapat mempermudah proses [13]. Secara keseluruhan, tes usability perangkat lunak jarang dikembangkan dan diimplementasikan karena berhubungan dengan masalah manajemen data, persyaratan, jadwal dan sumber daya yang tersedia dan bahkan diskusi pengguna-pembuat sistem yang sering. Kualitas perangkat lunak juga merupakan ukuran yang menunjukkan bahwa standar kualitas yang diacu telah tercapai. Keberhasilan suatu perangkat lunak ditentukan oleh kualitas.

Merujuk pada beberapa penelitian sebelumnya seperti pada penelitian Wahono dan Dias Prihatmoko yang membahas tentang perancangan user interface berbasis mobile untuk sistem otomatisasi rumah memanfaatkan internet dan OpenHAB [14], lalu ada dari Fauzan dan Fiqiana tentang aplikasi rumah pintar (smart home) pengendali peralatan elektronik rumah tangga berbasis web [2], selanjutnya dari Muslihudin dan kawan-kawan tentang impelementasi aplikasi rumah pintar berbasis android dengan arduino microcontroller [15], lalu ada dari Dedi Rianto tentang pengukuran usability sistem menggunakan use qusetionnaire pada aplikasi android [16], dan dari Hadyan Setiawan dan kawan-kawan tentang perancangan aplikasi smart home berbasis android untuk pengendalian keamanan rumah dengan menggunakan android studio [4]. Riset yang penulis lakukan berfokus pada analisis dari user experience dari aplikasi smart home yang diajukan dan tidak berfokus pada perangkat keras atau IOT didalam smart home itu sendiri, serta menggunakan USE Questionnaire.

\section{METODOLOGI PENELITIAN}

Metode waterfall merupakan metode 
pengembangan untuk pengembangan perangkat lunak aplikasi smart home. Metode waterfall merupakan metode terstruktur untuk setiap tahap pengembangan [17]. Prosedur pengujian usability adalah metode pengujian yang digunakan untuk mengevaluasi pengalaman pengguna dalam aplikasi rumah cerdas.

Konsep usability adalah untuk mengetahui bagaimana pengguna dapat mempelajari dan menggunakan produk mereka untuk mencapai tujuan mereka dan bagaimana aplikasi yang mereka gunakan memuaskan pelanggan [18]. Perangkat lunak dapat digunakan secara efektif oleh pengguna ketika pengguna akhir puas.

\section{Analisis Kebutuhan}

Pada fase ini dilakukan analisis masalah apa saja yang terdapat pada perancangan user interface pada aplikasi smart home dan bagaimana user experience yang dilakukan dengan aplikasi smart home, dan software mana yang dapat digunakan untuk mengembangkan sistem dan hardware mana yang dapat menjalankan software [19]. Perangkat lunak yang dibangun adalah aplikasi seluler yang digunakan pengguna untuk menjalankan aplikasi rumah cerdas.

\section{Metode Pengumpulan Data}

Dalam penelitian deskriptif dengan pendekatan kuantitatif data yang dibutuhkan untuk penelitian ini dikumpulkan [20]. Metode kuantitatif adalah cara untuk memperoleh data tentang pendapat, perilaku dan keyakinan dalam penelitian sebelumnya atau saat ini untuk menguji beberapa hipotesis [21].

\section{Perancangan Sistem}

Perancangan sistem kemudian akan dilakukan ketika kebutuhan untuk pengembangan telah diketahui. Desain sistem mencakup antarmuka pengguna, penggunaan kasus dan persiapan komponen icon, warna, font, dan desain aplikasi [22].

\section{Use case Diagram}

Penggunaan diagram kasus untuk menggambarkan komponen atau interaksi perangkat lunak pengguna.

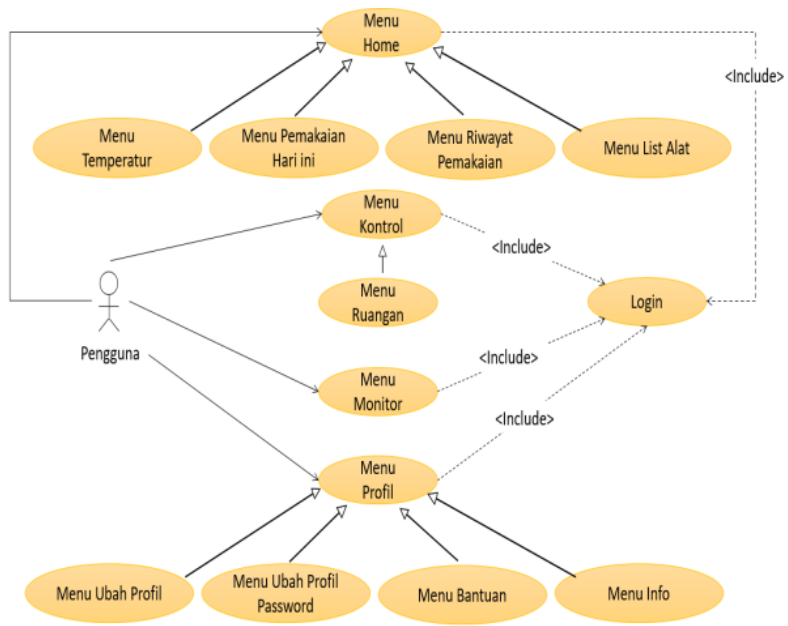

Gambar 1. Use case Diagram

Use case diagram terdapat aktor yaitu pengguna yang memiliki relasi assosiasi ke use case menu home, use case mеnu kontrol, use case menu monitor, dan use case menu profil. Dan dari ke use case menu home, use case menu kontrol, use case menu monitor, dan use case menu profil terdapat relasi include yang mengarah ke use case login. Artinya setiap pengguna yang ingin mengakses setiap menu aplikasi diharuskan untuk login terlebih dahulu.Relasi generalization, relasi ini terdapat di use case menu home, use case menu kontrol,dan use case menu profil use case tersebut adalah parent-nya sedangkan use case child nya yaitu use case temperatur, use case pemakaian hari ini, use case list alat, use case riwayat pemakaian, use case menu ruangan, use case menu mengubah profil, use case menu untuk mengubah password, use case menu bantuan, dan use case info. 


\section{Pengujian Kuisioner}

Pewawancara melakukan ini untuk mendapatkan pengalaman pengguna dari aplikasi yang diuji dengan meberikan pertanyaan, khususnya apa yang dilihat dan dirasakan pengguna selama tugas tertentu [23]. Angket diberikan kepada pewawancara. Kuesioner mencakup 13 pertanyaan yang mewakili lima aspek usability.

Tabel 1. Kuisioner

\begin{tabular}{|c|c|c|c|c|c|}
\hline \multirow{2}{*}{ No } & \multirow{2}{*}{ Pertanyaan } & \multicolumn{4}{|c|}{ Aspek Usability } \\
\hline & & LR EF & MR & ER & SF \\
\hline \multicolumn{6}{|c|}{ Aplikasi } \\
\hline 1 & $\begin{array}{l}\text { Apakah pada user interface aplikasi Smart Home dapat } \\
\text { anda kenali? }\end{array}$ & & & & \\
\hline 2 & $\begin{array}{l}\text { Menurut anda apakah aplikasi Smart Home gampang } \\
\text { digunakan? }\end{array}$ & & & & \\
\hline 3 & $\begin{array}{l}\text { Apakah penampilan warna di aplikasi Smart Home enak } \\
\text { dilihat dan tidak menimbulkan rasa bosan? }\end{array}$ & & & & \\
\hline \multicolumn{6}{|c|}{ Pengguna (User) } \\
\hline 4 & Apakah fungsi dari fitur yang ada berjalan dengan baik? & & & & \\
\hline 5 & Apakah respon aplikasi baik terhadap pengguna? & & & & \\
\hline 6 & $\begin{array}{l}\text { Apakah tulisan yang ada di dalam aplikasi Smart Home } \\
\text { mudah dibaca? }\end{array}$ & & & & \\
\hline 7 & $\begin{array}{l}\text { Apakah mudah untuk mematikan /menyalakan alat } \\
\text { elektronik di aplikasi Smart Home? }\end{array}$ & & & & \\
\hline 8 & Apakah ikon, gambar dan yang ada dapat dipahami? & & & & \\
\hline
\end{tabular}

\section{Interaksi (Interaction)}

9 Bahasa dalam aplikasi Smart Home mudah di mengerti?

10 Apakah usability yang ada sesuai dengan tujuan awal aplikasi?

11 Apakah jenis huruf yang digunakan pada aplikasi smart home mudah dibaca?

12 Apakah dari segi keamanan aplikasi sudah mengindikasikan jaminan aman?

13 Apakah penampilan dan menu Aplikasi Smart Home mudah untuk anda ingat?

Keterangan:

$$
\begin{aligned}
& \mathrm{LR}=\text { Learnability } \\
& \mathrm{EF}=\text { Efficiency } \\
& \mathrm{MR}=\text { Memorability } \\
& \mathrm{ER}=\text { Error } \\
& \mathrm{SF}=\text { Satisfaction }
\end{aligned}
$$

\section{Penentuan Skor Jawaban.}

Nilai jawaban adalah nilai jawaban responden. Kuesioner yang dibagikan kepada responden kemudian diperiksa dengan menggunakan skala likert dan dihitung. 
Tabel 2. Skala Likert

\begin{tabular}{cc}
\hline Skala Jawaban & Nilai \\
\hline Sangat Setuju & 5 \\
\hline Setuju & 4 \\
\hline Kurang Setuju & 3 \\
\hline Tidak Setuju & 2 \\
\hline Sangat Tidak Setuju & 1 \\
\hline
\end{tabular}

\section{Penentuan Skor Ideal}

Pada skala penilaian, teknik analisis skala Likert adalah 1 sampai 5. Hasil maksimal 5 (100\%) dan skor minimal 1 (20 persen dari skor maksimal). Nilai ini kemudian menginterpretasikan skor tanggapan responden dalam skala penilaian, dengan skala penilaian diperoleh data mentah berupa angka-angka yang kemudian diinterpretasikan secara kualitatif. Penyesuaian interpretasi dilakukan karena perangkat lunak dikembangkan melalui uji kelayakan. Kriteria yang digunakan untuk interpretasi skor dalam pengelolaan hasil survei seperti pada tabel 3:

Tabel 3 Interpretasi Skala Likert

\begin{tabular}{cll}
\hline No. & Persentase & Interpretasi \\
\hline 1 & $0 \%-20 \%$ & Rendah Sekali \\
\hline 2 & $21 \%-40 \%$ & Rendah \\
\hline 3 & $41 \%-60 \%$ & Cukup Tinggi \\
\hline 4 & $61 \%-80 \%$ & Tinggi \\
\hline 5 & $81 \%-100 \%$ & Sangat Tinggi \\
\hline
\end{tabular}

Sumber : Lalu Sulistiawan Akbar \& Dkk, 2019.

\section{Persentase Skor}

Rumus berikut dapat digunakan, mengingat kita mengetahui total skor pengambilan data berbentuk jawaban responden melalui persentase persetujuan:

$\boldsymbol{p}=\frac{\boldsymbol{f}}{\boldsymbol{n}} \boldsymbol{x} 100$

Keterangan:

$\boldsymbol{p}$ : Persentase

$\boldsymbol{f}$ : Frekuensi jawaban

$\boldsymbol{n}$ : Jumlah skor ideal 100: Bilangan tetap
HASIL

Aplikasi Smart Home berbasis Android. Aplikasi hanya dapat dijalankan melalui aplikasi Android yang digunakan secara efisien dan benar sesuai dengan persyaratan sistem untuk mengontrol dan memantau perangkat elektronik melalui smartphone. Pembahasan yang dihimpun melalui penelitian ini adalah tentang implementasi hasil uji usability aplikasi smart home.

\section{Implementasi Antarmuka.}

Pada Gambar 2 terdapat menu home, menu kontrol dan menu monitor, Menu home berisi menu temperatur untuk menampilkan suhu ruangan saat ini, menu pemakaian hari ini untuk menampilkan pemakaian listrik hari ini, menu list alat untuk menampilkan seluruh alat eletronik yang terhubung dengan aplikasi, menu riwayat pemakaian untuk menampilkan data pemakaian listrik perbulan, menu status alat untuk melihat status alat saat di aktifkan dan matikan. Di halaman menu kontrolberisikan list ruangan dan juga tombol untuk mematikan semua alat elektronik. Di halaman menu monitor menampilkan informasi list ruangan,alat elektronik yang sedang aktif, waktu pengaktifan alat elektronik, info pemakaian daya,dan suhu ruangan.
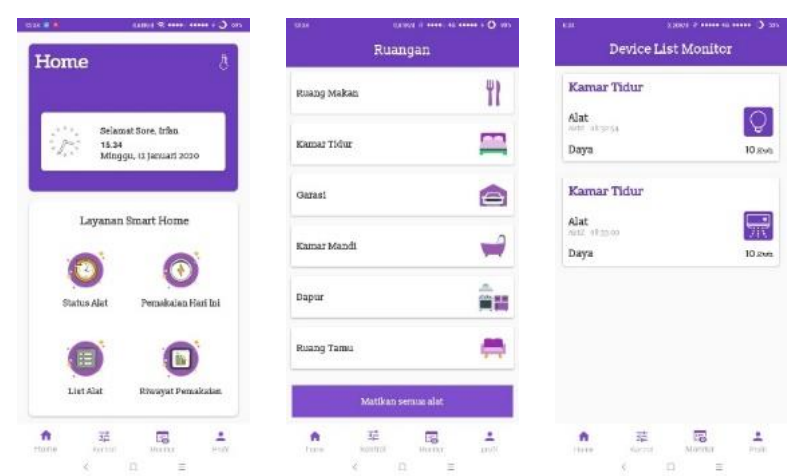

Gambar 2. Menu Home, Kontrol \& Monitor

Sebanyak 50 mahasiswa Informatika melakukan uji usability. Tes ini dilakukan dengan menggunakan alat USE Questionnaire

Corresponding Author: Muhammad Bambang Firdaus 
yang berisi 13 pertanyaan yang diuji secara valid.

a. Pengujian berdasarkan aspek sistem, aspek interaksi, dan aspek user.

Tabel 4. Persentase Skor Aspek Sistem, Interaksi, dan User

\begin{tabular}{cll}
\hline No. & Aspek & Persentase \\
\hline 1 & Sistem & $87.1 \%$ \\
\hline 2 & User & $88.24 \%$ \\
\hline 3 & Interaksi & $87.04 \%$ \\
\hline
\end{tabular}

Berdasarkan dari tabel diatas untuk aspek interaksi hasil persentase skor yang diperoleh adalah $87.1 \%$ dengan kategori skor sangat tinggi. Untuk aspek sistem hasil persentase skor yang diperoleh adalah $88.24 \%$ dengan kategori skor sangat tinggi. Selanjutnya untuk aspek user hasil persentase skor yang diperoleh adalah 87.04\% dengan kategori skor sangat tinggi.

b. Pengujian berasarkan aspek Usability.

Tabel 5. Persentase Skor Aspek Usability

\begin{tabular}{clc}
\hline No. & Aspek & Persentase \\
\hline 1 & Learn Ability & $87.34 \%$ \\
\hline 2 & Memorability & $87.36 \%$ \\
\hline 3 & Efficiency & $88.1 \%$ \\
\hline 4 & Error & $88.4 \%$ \\
\hline 5 & Satisfaction & $87.4 \%$ \\
\hline
\end{tabular}

Berdasarkan dari tabel diatas untuk aspek learnability hasil persentase skor yang diperoleh adalah $87.34 \%$ dengan kategori skor sangat tinggi. Untuk aspek efficiency hasil persentase skor yang diperoleh adalah $88.1 \%$ dengan kategori skor sangat tinggi. Selanjutnya untuk aspek memorability hasil persentase skor yang diperoleh adalah $87.36 \%$ dengan kategori skor sangat tinggi. Untuk aspek error hasil persentase skor yang diperoleh adalah $88.4 \%$ dengan kategori skor sangat tinggi. Kemudian untuk aspek satisfaction hasil persentase skor yang diperoleh adalah $87.4 \%$ dengan kategori skor sangat tinggi.

c. Pengujian berdasrkan seluruh aspek.

Hasil dari pengujian Usability menurut 50 koresponden yang telah menggunakan aplikasi smart home pada aspek Learnability mendapatkan skor sebesar $87.34 \%$, aspek Efficiency mendapatkan skor sebesar $88.1 \%$, aspek Memorability mendapatkan skor sebesar $87.36 \%$, aspek Error mendapatkan skor sebesar $88.4 \%$, aspek Satisfaction mendapatkan skor sebesar $87.4 \%$.Hasil dari pengujian Usability menurut 50 koresponden yang telah menggunakan aplikasi smart home pada aspek Interaksi mendapatkan skor sebesar $87.1 \%$, aspek Sistem mendapatkan skor sebesar $88.24 \%$, dan aspek User mendapatkan skor sebesar 87.04\%.Hasil dari User Experience terhadap desain dari aplikasi smart home menurut 50 koresponden yang telah menggunakan aplikasi smart home memperoleh skor sebesar $87.50 \%$ dengan perolehan kategori sangat tinggi.

\section{KESIMPULAN}

Rancangan User Interface pada aplikasi smart home yang dibangun dengan berbasis android sudah memudahkan pengguna dalam menggunakan aplikasi smart home. Hal itu dibuktikan dari Hasil dari pengujian Usability menurut 50 koresponden yang telah menggunakan aplikasi smart home pada aspek Interaksi mendapatkan skor sebesar $87.1 \%$, aspek Sistem mendapatkan skor sebesar $88.24 \%$, dan aspek User mendapatkan skor sebesar $87.04 \%$. Hasil dari pengujian Usability pada aspek Learnability mendapatkan skor sebesar $87.34 \%$, aspek Efficiency mendapatkan skor sebesar $88.1 \%$, aspek Memorability mendapatkan skor sebesar $87.36 \%$, aspek Error 
mendapatkan skor sebesar 88.4\%, aspek Satisfaction mendapatkan skor sebesar $87.4 \%$.

User Experience terhadap desain dari aplikasi smart home menurut 50 koresponden yang telah menggunakan aplikasi smart home memperoleh skor sebesar $87.50 \%$ dengan perolehan kategori sangat tinggi.

\section{DAFTAR PUSTAKA}

[1] A. T. Sutanto, H. N. Palit, and R. Lim, "Aplikasi Mobile untuk Kendali Simulasi Smart Home Berbasis Lokasi," J. Infra Petra, pp. 2-7, 2019.

[2] F. Masykur and F. Prasetiyowati, "Aplikasi Rumah Pintar (Smart Home) Pengendali Peralatan Elektronik Rumah Tangga Berbasis Web," J. Teknol. Inf. dan Ilmu Komput., vol. 3, no. 1, p. 51, 2016, doi: 10.25126/jtiik.201631156.

[3] S. B. Pribadi and E. Prianto, "Rancang Bangun Smart-Home (Aplikasi Instalasi Perangkat Energi Alternatif Sinar Matahari Dalam Disain Rumah Tinggal)," Modul, vol. 18 , no. 1, p. 26, 2018, doi: 10.14710/mdl.18.1.2018.26-32.

[4] H. Setiawan, A. Sofwan, and Y. Christyono, "Perancangan Aplikasi Smart Home Berbasis Android Untuk Pengendalian Keamanan Rumah Dengan Menggunakan Android Studio," Transient, vol. 6, no. 3, p. 503, 2017, doi: 10.14710/transient.6.3.503513.

[5] F. Nofiyanti et al., "EKRANISASI KARYA SASTRA TRAVELING SEBAGAI MEDIA PROMOSI WISATA INDONESIA," vol. 3, no. 3, pp. 1-16, 2019.

[6] N. Dengen, H. S. Pakpahan, G. F. Putra, M. B. Firdaus, R. Wardhana, and A. Tejawati, "An Augmented Reality Model Physical Transformation Learning," ICEEIE 2019 Int. Conf. Electr. Electron. Inf. Eng. Emerg. Innov. Technol. Sustain. Futur., pp. 255259, 2019, doi: 10.1109/ICEEIE47180.2019.8981444.

[7] M. Kristian, I. Fitri, and A. Gunaryati, "Implementation of Augmented Reality for Introduction To Android Based Mammalian Animals Using The Marker Based Tracking Method," JISA(Jurnal Inform. dan Sains), vol. 3, no. 1, pp. 1-6, 2020, doi: 10.31326/jisa.v3i1.623.
[8] V. Frendiana and D. Widhiantoro, "Desain UI dan UX pada Aplikasi Android Coronavirus Disease 2019 ( COVID-19 )," J. Ilmu Komput. dan Desain Komun. Vis. Vol., vol. 5, no. 2, pp. 85-93, 2020.

[9] J. Fang, Z. Zhao, C. Wen, and R. Wang, "Design and performance attributes driving mobile travel application engagement," Int. J. Inf. Manage., vol. 37, no. 4, pp. 269-283, 2017, doi: 10.1016/j.ijinfomgt.2017.03.003.

[10] S. Kikitamara and A. A. Noviyanti, "A conceptual model of user experience in scrum practice," Proc. 2018 10th Int. Conf. Inf. Technol. Electr. Eng. Smart Technol. Better Soc. ICITEE 2018, pp. 581-586, 2018, doi: 10.1109/ICITEED.2018.8534905.

[11] M. B. Firdaus, I. M. Patulak, A. Tejawati, A. Bryantama, G. M. Putra, and H. S. Pakpahan, "Agile-scrum Software Development Monitoring System," ICEEIE 2019 - Int. Conf. Electr. Electron. Inf. Eng. Emerg. Innov. Technol. Sustain. Futur., pp. 288-293, 2019, doi: 10.1109/ICEEIE47180.2019.8981471.

[12] N. M. Farhany, S. Andryana, and R. T. Komalasari, "Aplikasi Augmented Reality Sebagai Media Informasi Museum Fatahillah Dan Museum Wayang Menggunakan Metode Markerless," J. ELTIKOM, vol. 3, no. 2, pp. 104-111, 2019, doi: 10.31961/eltikom.v3i2.140.

[13] N. Puspitasari, M. B. Firdaus, C. A. Haris, and H. J. Setyadi, "An application of the UTAUT model for analysis of adoption of integrated license service information system," Procedia Comput. Sci., vol. 161, pp. 57-65, 2019, doi: 10.1016/j.procs.2019.11.099.

[14] B. B. Wahono and D. Prihatmoko, "Perancangan User Interface Berbasis Mobile Untuk Sistem Otomatisasi Rumah Memanfaatkan Internet dan OpenHAB," JUITA J. Inform., vol. 5, no. 2, p. 95, 2018, doi: 10.30595/juita.v5i2.1850.

[15] M. Muslihudin, W. Renvilia, Taufiq, A. Andoyo, and F. Susanto, "Implementasi Aplikasi Rumah Pintar Berbasis Android Dengan Arduino Microcontroller," $J$. Keteknikan dan Sains, vol. 1, no. 1, pp. 2331, 2018.

[16] D. R. Rahadi, "Pengukuran Usability Sistem Menggunakan Use Questionnaire Pada Aplikasi Android Interface pengguna 
Android didasarkan pada manipulasi langsung menggunakan masukan sentuh yang serupa dengan tindakan di dunia nyata , seperti menggesek ( swiping ), mengetuk," J. Sist. Inf., vol. 6, no. 1, pp. 661-671, 2014.

[17] I. K. A. A. Putra and I. G. N. A. C. Putra, "Development of Augmented Reality Application for Canang Education Using Marker-Based Tracking Method," JELIKU (Jurnal Elektron. Ilmu Komput. Udayana), vol. 9, no. 3, p. 365, 2021, doi: 10.24843/jlk.2021.v09.i03.p07.

[18] G. Feoh and R. P. Wiryadikara, "Pengujian Functional Suitability Pada Implementasi," pp. 203-212, 2019.

[19] A. Tejawati, M. B. Firdaus, M. N. Ihwan, F. Alameka, and M. K. Anam, "Prototipe Media Pembelajaran Rambu Lalu Lintas Berbasis Android," Metik J., vol. 5, no. 1, pp. 12-18, 2021, doi: 10.47002/metik.v5i1.210.

[20] N. Puspitasari, E. Budiman, Y. N. Sulaiman, and M. B. Firdaus, "Microservice API Implementation for E-Government Service Interoperability," J. Phys. Conf. Ser., vol. 1807 , no. 1, 2021, doi: $10.1088 / 1742-$ 6596/1807/1/012005.

[21] M. B. Firdaus, N. Puspitasari, E. Budiman, J. A. Widians, and N. Bayti, "Analysis of the effect of quality mulawarman university language center websites on user satisfaction using the webqual 4.0 method," Proc. ICAITI 2019 - 2nd Int. Conf. Appl. Inf. Technol. Innov. Explor. Futur. Technol. Appl. Inf. Technol. Innov., pp. 126-132, 2019, doi: 10.1109/ICAITI48442.2019.8982143.

[22] F. Suandi, S. Sibagariang, Y. K. Amalia, and M. B. Firdaus, "Usability Testing Situs Web Politeknik Negeri Batam Menggunakan Metode Eye Tracking," J. Integr., vol. 13, no. 1, pp. 78-83, 2021.

[23] M. B. Firdaus, "Pengembangan Alat Ukur Keterbukaan Informasi Publik pada Situs Web Pemerintah Studi Kasus Kabupaten Kutai Kartanegara," J. Ilm. Ilmu Komput., vol. 3, no. 1, pp. 7-13, 2017. 